\title{
Uma breve revisão da gramaticografia hispânica
}

\section{A brief review of the Hispanic grammaticography}

\author{
Leandro Silveira de ARAUJO * \\ Fernanda Silva FREITAS **
}

\begin{abstract}
RESUMO: Neste trabalho, consultamos algumas gramáticas de língua espanhola a fim de levantar dados textuais e extratextuais que caracterizam a gramaticografia hispânica. Os dados analisados foram coletados em sites de acervo de universidades brasileiras e estrangeiras. Esses dados foram tratados considerando fatores como: ano de publicação, local de publicação, origem geográfica do autor, finalidade etc. Entre outros, verificamos que a Espanha responde pela maior parte das obras publicadas ao longo dos séculos. Foi observado também que o século $X X$ concentra o maior número de obras publicadas. Destacamos a importância desse tipo de abordagem para compreender melhor as mudanças ocorridas na gramaticografia hispânica, bem como alguns dos fatores que suscitam essas modificações
\end{abstract}

PALAVRAS-CHAVE: Gramaticografia. Norma linguística. Língua espanhola.

\begin{abstract}
In this paper, we have consulted some Spanish grammars in order to obtain textual and extratextual data that characterize the Hispanic grammaticography. The data were collected on sites from Brazilian and foreign universities. These data were processed considering factors such as: year of publication, place of publication, geographical origin of the author, purpose, etc. Among others, we have found that Spain accounts for most of the works published over the centuries. It was also observed that the 20th century concentrates the largest number of published works. We emphasize the importance of this type of approach to better understand the changes that occurred in Hispanic grammaticography, as well as some of the factors that give rise to these modifications.
\end{abstract}

KEYWORDS: Grammaticography. Linguistic norm. Spanish.

\footnotetext{
Doutorado em Linguística e Língua Portuguesa. Professor adjunto na UFU. ORCID: https://orcid.org/0000-0001-8518-1266. araujols@ufu.br.

** Graduação em Letras: Espanhol e Literaturas de Língua Espanhola, UFU. ORCID: https://orcid.org/0000-0001-5355-120X. fernanda.sfreitas@ufu.br.
} 


\section{Introdução}

Este estudo voltou-se à análise do processo de produção de gramáticas em língua espanhola a fim de identificar e de descrever algumas características de manuais que versaram sobre o funcionamento do castelhano. Contudo, antes de explorar propriamente essa temática, de justificá-la e de apresentar mais detalhadamente os objetivos pautados, é importante ressaltar que essa discussão é permeada por uma definição prévia de "norma linguística" e de sua relação com o ser humano e com a sociedade em que se insere.

Segundo nos explica Múgica (2007), o estudo da norma linguística envolve um campo bastante intrincado por lidar com (1) trabalhos que, pautados em diferentes perspectivas, dedicam-se a discuti-la e defini-la de diferentes maneiras; (2) por tratarse de um fenômeno da linguagem - que, como sabemos, é muito complexa, já que está em constante construção - e, finalmente, (3) por ser um fenômeno relativo. Contudo, a fim de melhor definirmos a "norma da língua" - o conceito fundamental que percorre a essência desta proposta -, recorremos a Eugenio Coseriu (1962), para quem norma é

un sistema de realizaciones obligadas, de imposiciones sociales y culturales, y varía según la comunidad. Dentro de la misma comunidad lingüística nacional y dentro del mismo sistema funcional pueden comprobarse varias normas (lenguaje familiar, lenguaje popular, lengua literaria, lenguaje elevado, lenguaje vulgar, etcétera) (COSERIU, 1962, p. 98).

Cabe pontuar que, sob a perspectiva instaurada pelo autor, não se está pensando no sentido mais corrente de norma, como algo "estabelecido ou imposto segundo critérios de correção e valoração subjetiva", normalmente registrada nos manuais a que este trabalho se aterá. A norma linguística a que se refere Coseriu (1962) 
é aquela que contém "o que no falar concreto é repetição de modelos anteriores", isto é, que elimina tudo aquilo que é "totalmente inédito, variante individual, ocasional ou momentâneo" e conserva "somente os aspectos comuns que se comprovam nos atos considerados". Assim, atribui-se à norma da língua aquilo que é legitimado, reconhecido e praticado por todos na comunidade e, como tal, é constructo naturalmente concebido no seio da sociedade e não artificialmente imposto por uma instituição ou por um grupo.

A concepção de norma linguística proposta por Coseriu (1962) origina-se do rearranjo da dicotomia saussuriana língua vs. fala, a qual passa a ser redefinida como sistema vs. norma vs. fala. "Nesta tríade, a fala continua na ordem do individual, mas o conceito de língua é modificado. Coseriu chama de língua o sistema articulado com suas normas, ou seja, com suas variantes linguísticas" (PIETROFORTE, 2002, p. 92). Dessa maneira, a noção de língua passa a envolver o sistema - domínio de todos os falantes de uma mesma língua - e as normas - variedades de domínio de grupos sociais e regionais.

Valendo-se de uma perspectiva antropológica, Aléong (2011) define a norma da língua como variável e relativa, posto que se define na heterogeneidade da sociedade:

Nesta concepção de sociedade [heterogênea], as normas sociais ou regras do comportamento são variadas e relativas. Variadas porque os agrupamentos constitutivos da sociedade também são variados, e relativas porque os juízos de valor só têm significação em relação ao grupo ou ao conjunto de referência no qual se situam os indivíduos. (ALÉONG, 2011, p. 145).

Uma vez que se considera que todo o comportamento social é regulado por normas, também a prática linguística será entendida como "o produto de uma hierarquização das múltiplas formas variantes" (ALÉONG, 2011, p. 148). Assim, a norma linguística funciona como referência para "os usos concretos pelos quais o indivíduo se apresenta em uma sociedade imediata" (ALÉONG, 2011, p. 149). É 
importante observar que não se trata de considerar um comportamento certo e os demais errados; pois, sob essa ótica, o uso efetivo da linguagem, por mais diversificado que possa ser, responde, na verdade, às coerções sociais e discursivas observáveis.

Contudo, concomitante à primeira concepção de norma apresentada, há também aquela norma tida como padrão ou como exemplar para o uso da língua. Conforme Aléong (2011), essa norma apresenta um caráter normativo, idealizado e definido por juízos de valor; de tal modo que, por não resultar de uma conduta linguística naturalmente criada no grupo e na situação em que a língua se instaura, ela pode se impor artificialmente como uma norma desconhecida pelo falante. Pois:

Codificada e consagrada num aparato de referência, essa norma é socialmente dominante no sentido de se impor como o ideal a respeitar nas circunstâncias que pedem um uso refletido ou monitorado da língua, isto é, nos usos oficiais, na imprensa escrita audiovisual, no sistema de ensino e na administração pública. (ALÉONG, 2011, p. 149).

Aléong (2011) observa a existência de três características compondo a norma exemplar: (1) um discurso da norma que categoriza o uso da língua como certo, errado, bom, mau, puro etc.; (2) um aparelho de referência que apresenta exemplos de uso (gramáticas, dicionários, academias e outros órgãos públicos) e (3) a difusão e a imposição constante graças ao "papel hegemônico de referência legítima em lugares estratégicos como a escola, a imprensa escrita, etc." (ALÉONG, 2011, p. 160). É justamente na análise desse aparelho de referência (gramática), que potencialmente registra a norma, é que se insere os objetivos deste trabalho.

Segundo Bagno (2007), essa percepção normativa pode se identificar com a "norma-padrão" e muitas vezes visa extinguir a diversidade linguística e favorecer, por meio de seu uso, uma variedade homogênea e idealmente compartilhada por todos. No entanto, origina-se um problema sociocultural quando se começa a tratar a língua apresentada pelas gramáticas e pelos dicionários como uma verdade eterna de 
uso, acreditando, por isso, na existência de uma única possibilidade de uso da língua: o da "norma-padrão".

Combatendo esse pensamento, os estudos da Sociolinguística revelam-nos que nenhuma língua se apresenta como uma entidade homogênea e que, portanto, toda língua deve ser representada por um conjunto de variedades. Desse modo, o que chamamos de "língua espanhola", na prática, envolve as diferentes maneiras de falar usadas pelos falantes argentinos, mexicanos, peruanos, equatorianos, colombianos, espanhóis, chilenos, entre outras tantas variedades não limitadas a fronteiras políticas.

Inserida nesse contexto, a escola tem o papel fundamental de romper com o mito da existência, tanto na língua materna como na língua estrangeira, de uma única forma certa de falar. Caberá ainda a essa instituição a formação do conhecimento plurilinguístico, que envolve o reconhecimento das formas mais vernaculares e o ensino das institucionalizadas como modelo. Obviamente que a escolha de uma gramática apropriada e o tratamento dado a ela no âmbito escolar são fatores de singular importância quando se quer refletir sobre língua e sobre seu funcionamento.

Com efeito, ao propor descrever gramáticas produzidas em língua espanhola ao longo da história, inserimos este trabalho no escopo do amplo cenário de discussão que envolve o conceito de norma linguística e os desdobramentos resultantes da relação do homem com a linguagem em forma de instrumentos normativos (gramáticas).

Nosso objetivo, portanto, é identificar quais são e como foram compostas as gramáticas da língua espanhola ao longo da história. Desse modo, interessou-nos registrar e catalogar os instrumentos de gramatização da língua espanhola a que tivemos acesso, definindo algumas de suas características textuais (categorização que faz da língua, por exemplo) e extratextuais (origem, autoria, data, propósito, público alvo, etc.). Uma vez delineados os traços que caracterizam esses manuais, acreditamos tornar viável o desenvolvimento futuro de análises mais apuradas, que permitam 
conhecer o objetivo e a concepção de língua delineados nas páginas desses manuais, bem como a sua recepção, a sua circulação e os seus efeitos causados nas sociedades hispânicas e entre aprendizes de espanhol como língua estrangeira.

Ao delinear a gramática e o seu entorno produtivo como objeto de análise, voltamo-nos ao que Aléong (2011) denominou "norma exemplar". Assim, esperamos entender quais são os fatores imbricados na produção dessa norma e como eles nos ajudam a entender as características específicas e gerais da gramaticografia hispânica. A seguir, compartilhamos nosso percurso metodológico a fim de melhor compreender a abrangência de nossa análise.

\section{Procedimentos de análise}

A metodologia adotada no presente estudo foi de cunho qualitativo exploratório, assumindo como procedimento de análise uma pesquisa documental, que compreende gramáticas voltadas à descrição e ao ensino da língua espanhola.

Para construir o compilado de gramáticas e de manuais de Língua Espanhola submetidos à análise, foi feita uma busca em sites de pesquisa de acervo bibliotecário de universidades nacionais e estrangeiras. Esse exame se deu em algumas das bibliotecas universitárias do Brasil (UFU, Unesp, Unicamp, USP) e de outros centros estrangeiros de referência na pesquisa sobre a língua espanhola (Universidad Complutense de Madrid, Universidad Autónoma de Madrid, Universidad Nacional de México e Instituto Caro y Cuervo). Nessa consulta, as palavras-chave utilizadas foram: 'gramática', 'lengua española', 'lengua castellana', 'español' e 'castellano'. Além disso, somaram-se ao corpus compilado, contribuições do acervo pessoal de pesquisadores residentes no Brasil.

Uma vez identificado o material nos sites das bibliotecas mencionadas, empreendemos uma busca pelas versões impressas ou digitalizadas desses manuais. Por motivo de acessibilidade, os esforços de coleta das obras impressas foram 
concentrados especialmente nas bibliotecas da Universidade Federal de Uberlândia (UFU) e da Universidade Estadual Paulista "Júlio de Mesquita Filho" (Unesp), respectivamente, nos campi Santa Mônica e Araraquara. Os dados encontrados foram compilados em um quadro de controle, no qual descrevemos detalhadamente as informações de cada uma das gramáticas. Considerando as obras identificadas em todos os acervos consultados, foram totalizados 108 registros diferentes de manuais e de gramáticas da língua espanhola.

No quadro de controle, foram descritas informações referentes às gramáticas catalogadas, tais como autoria, origem do autor, título da gramática, número de páginas, ano da primeira publicação, ano da edição do exemplar a que se teve acesso, cidade da publicação, editora, localização do exemplar no acervo e tipo de acesso ao documento pelo pesquisador. Essa última categoria foi criada para verificar quais obras possibilitarão realizar, futuramente, uma análise mais completa do tipo de análise e de concepção de língua assumido pelos autores. Nessa categoria, as gramáticas receberam uma de três classificações: Total (quando há o acesso à obra completa, seja em sites de domínio público, na impressa ou em PDF); Parcial (quando apenas se tem acesso à parte do material) e Nulo (quando não foi possível ter acesso algum à obra).

Como apresentamos mais adiante, a categorização dessas variáveis auxiliou na análise feita desses manuais, informando, entre outros, dados sobre momentos históricos e sobre espaços geográficos que mais se envolveram na descrição da língua castelhana e de suas variedades.

Concluída a primeira etapa de busca e de categorização, passamos, então, à tentativa de ter acesso, fosse total ou parcial, às obras referenciadas. Aquelas encontradas apenas em bibliotecas físicas tiveram apenas suas seções mais relevantes para este estudo digitalizadas: capa, ficha catalográfica, sumário, introdução e, quando presente, considerações sobre a visão de língua e gramática adotada na obra. Por isso, 
aparecem apontadas no quadro de controle de dados como "acesso parcial". Os manuais encontrados apenas online, mas que apresentavam links para sua versão completa em sites de domínio público, tiveram seus links salvos em uma tabela separada e constam como "acesso completo". Também foram considerados de "acesso completo" os itens disponibilizados através de acervo pessoal de pesquisadores.

Por fim, as entradas que não se encaixaram nas categorias anteriormente descritas foram registradas como "acesso nulo". Assim, observa-se que, dos 108 registros compilados, um total de $48 \%$ apresenta alguma possibilidade de acesso (52 obras), como está descrito no gráfico 1:

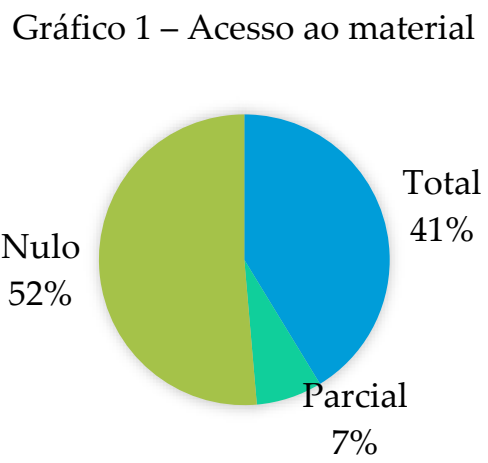

Fonte: própria.

Fundamentado nesse levantamento, iniciou-se então o processo de classificação dos manuais encontrados. Todos eles, independentemente da possibilidade de acesso, foram classificados considerando todos os fatores registrados no quadro de controle de dados, isto é, autor(es), origem do(s) autor(es), título da gramática, número de páginas, ano de publicação, ano da edição, cidade da publicação, editora, localização e acesso. Aqueles catalogados como "acesso parcial" ou como "total" poderão receber, em trabalhos futuros, um tratamento ainda mais direcionado no que diz respeito ao conceito de norma linguística assumido, por exemplo. Os dados das gramáticas a que não tivemos acesso foram coletados de informações oferecidas pelas bibliotecas ou por outros sites de busca. 
Tendo realizado esse registro, deu-se então o processo de análise dos dados, através de contagem simples e de separação por categoria desejada. Nessa abordagem, nos detivemos às informações que não dependiam da possibilidade de acesso total à obra para serem analisadas, possibilitando assim uma visão mais geral do corpus.

\section{Contribuições à gramaticografia hispânica}

Os dados encontrados ao longo deste estudo foram agrupados e tratados segundo os diferentes fatores já apresentados, gerando dados estatísticos que consideramos relevantes para conhecer melhor a gramaticografia da língua espanhola. Nesta discussão, atentaremo-nos aos fatores: tempo, espaço, finalidade e autor.

Paralelamente, ainda foi possível realizar cruzamentos de dados, de modo a visualizar algumas informações mais robustas. Assim, observamos as gramáticas considerando a relação dos fatores "tempo x espaço" e "tempo x finalidade".

Além disso, foi possível comparar os resultados de nosso estudo com parte dos dados compartilhados pelo trabalho de Calero Vaquera (2016), no qual se apresenta um recorte da história da produção gramatical em língua espanhola. Julgamos pertinente realizar esta comparação para verificar se os resultados que obtivemos com o corpus aqui analisado têm confirmação e, ainda, para observar quais aspectos demandam maior atenção.

Apresentamos a seguir os dados estatísticos e as discussões levantadas em cada etapa de tratamento de dados desta pesquisa, agrupados pelos seguintes critérios de análise: origem geográfica, tempo, autor e finalidade (tema).

\subsection{Origem geográfica}

No referente à localização geográfica, foram realizadas duas categorizações: quanto à origem do autor e quanto ao local de publicação da obra. Nessa etapa, não foram encontrados os dados referentes à nacionalidade do autor em 19 obras. Por isso, 
as estatísticas que seguem foram geradas considerando apenas aquelas gramáticas que possuíam a informação de origem do autor, isto é, 89 manuais.

É importante comentar que analisamos esse grupo em dois momentos: primeiro, limitamo-nos aos manuais que apresentaram o nome de apenas um país na categoria "Origem do autor" e, posteriormente, aos que apresentaram dois ou mais países. Nesses casos, o local de nascimento não é o mesmo do lugar onde o autor passou maior parte de sua vida e da produção bibliográfica.

Considerando o grupo total de gramáticas submetidas à análise da origem da autoria, 77 apresentaram referência a apenas um país por autor. Dentro desse grupo, foram mencionados ao todo 11 países, sendo Espanha, Argentina e Estados Unidos os três países mais incidentes - respectivamente, com 54, 8 e 4 registros. Separando os resultados por região, observamos que a zona mais referenciada foi a Europa, com 58 registros; seguida pela América Hispânica, com 14 registros, e pela América Anglófona, com 4 entradas.

Diante dessa informação, torna-se inquestionável o papel que a Espanha adquiriu frente à função de descrever a língua espanhola e inclusive de desenvolver políticas linguísticas, como a produção de gramáticas. Paralelamente, é ainda pertinente destacar o número de gramáticas produzidas por autores estadunidenses, pois, apesar de muito menor que a produção espanhola, ainda se destaca frente a outros países, que inclusive têm o espanhol como língua oficial. Em outros termos, parece que a produção de manuais por norte-americanos pode ser um indício que evidencia a importância do castelhano para esse povo - que, como sabemos, mantém intenso contato linguístico com o idioma.

As 12 gramáticas restantes correspondem à parcela de manuais cujos autores estão relacionados a mais de um país. Autores que têm nacionalidade em um país, mas que sua produção escrita mais expressiva se deu em outro. Nesse grupo, registramos a ocorrência de 13 países diferentes. Nesse segmento, os três países mais citados foram 
Espanha (7), Argentina (4) e Chile (3). Separados por região, a América hispânica apresenta maior frequência: 11 vezes, seguida por Espanha (7 vezes).

Ao comparar os resultados das duas análises supracitadas (uma ou mais nacionalidade), observou-se que os dois países mais incidentes seguem sendo Espanha e Argentina com, respectivamente, 61 e 12 menções. A cifra argentina mostra-se ainda mais relevante quando se leva em conta o número total de menções a países latinoamericanos: 25. Assim, somente a Argentina representa quase 50\% das ocorrências de autores nascidos ou com maior produção em países da América Latina.

Dirigindo a análise ao fator que controlou o local de publicação das obras, novamente se viu grande expressividade da Espanha. Dentre as cinco cidades com maior ocorrência, as duas primeiras são cidades espanholas. Madrid é a primeira, com 60 das 108 obras (56\%), e é seguida por Barcelona, com 8 publicações. Essas duas primeiras cidades representam $63 \%$ do total das gramáticas consultadas - a esse número, ainda poderíamos somar as outras cidades espanholas que aparecem com uma ou com duas publicações (Alcoi, Ávila, Granada, León, Pamplona, Salamanca, Santander, Valencia), totalizando 77 produções (71\%).

Entre as hispano-americanas, destacam-se a cidade de Buenos Aires, com 7 obras, e a Cidade do México, com 3. Desse modo, a capital argentina apresenta-se como o segundo maior centro editorial entre o acervo tomado como base.

O cruzamento dos dados referentes ao local e ao ano de publicação mostra que a dominância espanhola não se apresentou apenas na contagem geral, mas também quando separamos as gramáticas por século de publicação. Em praticamente todos os séculos em que identificamos manuais, o país com maior incidência foi a Espanha ${ }^{1}$ (Tabela 1). Tal informação evidencia a localização do maior mercado editorial de

\footnotetext{
${ }^{1}$ Apenas no século XVII a Espanha não se mostra como maioria, posto que há um empate com a América Hispânica.
} 
produção de gramáticas de língua espanhola e como a consolidação desse mercado ocorreu com o avançar dos séculos.

Tabela 1 - Da distribuição dos locais de publicação ao longo dos séculos.

\begin{tabular}{c|c|c|c|c|c|c|c}
\cline { 2 - 7 } & $\begin{array}{c}\text { Séc. } \\
\text { XV }\end{array}$ & $\begin{array}{c}\text { Séc. } \\
\text { XVII }\end{array}$ & $\begin{array}{c}\text { Séc. } \\
\text { XVIII }\end{array}$ & $\begin{array}{c}\text { Séc. } \\
\text { XIX }\end{array}$ & $\begin{array}{c}\text { Séc. } \\
\mathbf{X X}\end{array}$ & $\begin{array}{c}\text { Séc. } \\
\text { XXI }\end{array}$ & Total \\
\hline Espanha & 1 & 1 & 1 & 16 & 44 & 14 & 77 \\
\hline Amér. Hisp. & 0 & 1 & 0 & 2 & 8 & 7 & 18 \\
\hline Amér. Anglóf. & 0 & 0 & 0 & 1 & 4 & 0 & 5 \\
\hline Outros & 0 & 0 & 0 & 3 & 3 & 2 & 8 \\
\hline
\end{tabular}

Fonte: própria.

Ainda na Tabela 1, merece destaque o surgimento, a partir do século XIX, de outros países que não têm o espanhol como língua oficial, mas que atuam na publicação de gramáticas nesse idioma. Todos esses países são fronteiriços com países hispânicos e, entre eles, destacam-se o Brasil e os Estados Unidos, com cinco gramáticas cada.

Frente à grande expressividade da Espanha no corpus aqui estudado, é importante destacar a necessidade de ampliar as bases de consulta, posto que nesta pesquisa foi dada especial atenção a universidades espanholas (UCM e UAM). Assim, é possível que outros países apresentem incidência maior que as apresentadas neste trabalho, ou, ainda, que a Espanha apresente menor domínio, caso seja feita uma busca com maior abrangência.

\subsection{Tempo}

Em seguida, realizamos a análise das obras considerando o ano de publicação². Nessa categoria, não conseguimos encontrar registros de apenas quatro gramáticas. Por isso, estimamos seu século de produção baseados nas informações encontradas

\footnotetext{
${ }^{2}$ Foi considerado o ano de publicação da primeira edição da obra, e não o ano da edição.
} 
sobre seus respectivos autores e constatamos que todas as quatro foram produzidas no século XX. Em nossa análise, as obras foram organizadas por século (Gráfico 2).

Gráfico 2 - Da distribuição das gramáticas por séculos.

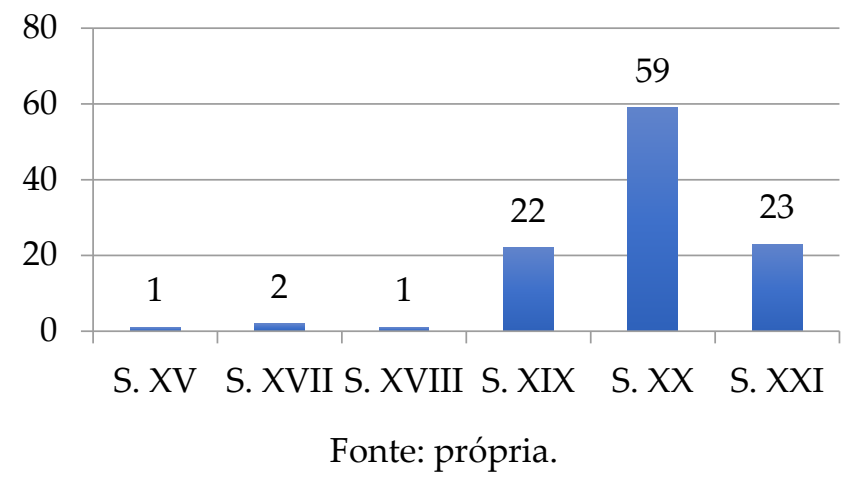

Com base nessa distribuição, observamos que o período histórico com maior produção de gramáticas foi o século XX, com 59 obras produzidas (55\%), seguido pelo século XXI, com 23 gramáticas (21\%) e pelo século XIX, com 22 obras (20\%). O restante das produções está situado nos séculos XV (uma obra), XVII (duas obras) e XVIII (uma obra). Cabe alertar que apenas vivenciamos a segunda década do século XXI, o que demonstra um grande potencial de crescimento na escrita de gramáticas ainda neste século.

Esse resultado dialoga diretamente com o que defende Calero Vaquera (2016, p. 107), pois, segundo a autora, no século XIX é grande a produção de gramáticas principalmente didáticas - no território espanhol e em outros países hispânicos, como na Argentina. Ainda segundo explica Calero Vaquera (2016), dado crescimento é influenciado pela difusão da forte produção francesa de gramáticas na mesma época. Além disso, tem-se, no século XX, uma significativa mudança e um aprofundamento nos estudos linguísticos em todo o mundo, com novas vertentes e novas áreas de estudo surgindo e ganhando força. Assim, somadas as 23 gramáticas produzidas nas duas décadas do séc. XXI com a análise que realizamos, é possível identificar uma 
tendência crescente na produção de gramáticas de língua espanhola a partir do séc. XIX.

Esse movimento ascendente na produção de gramáticas em língua espanhola fica ainda mais evidente se analisarmos mais atentamente as gramáticas publicadas durante o século XX (1901 - 2000), fragmentando o período em grupos de duas décadas. Assim, no Gráfico 3, excluímos das 59 obras publicadas no século XX aquelas quatro cujo ano de publicação específico não foi possível encontrar, restando-nos apenas a informação do século. Conforme explicita o Gráfico 3, é possível verificar um aumento da produção de gramáticas à medida que se caminha para o final do século, sendo, portanto, o período entre 1981 e 2000 o que apresentou maior número de gramáticas publicadas (25).

Considerando as obras que não foram adicionadas ao corpus de análise e que foram mencionadas pelo trabalho de Calero Vaquera (2016), vale ressaltar que todas foram publicadas antes do século XX, com a maioria (19 gramáticas) pertencente ao século XIX e com 15 obras publicadas no século XVIII. Essa proporção, em contraste com a única gramática no corpus que compilamos que data do século XVIII, revela que a produção de gramáticas durante esse século foi maior que a identificada em nosso estudo. Comportamento que parece indicar que o movimento de ascensão na produção de gramáticas em língua espanhola inicia-se já no século XVIII, alcançando maior expansão nas últimas décadas do século XX e nas décadas iniciais do século XXI. 
Gráfico 3 - Do número de gramáticas publicadas ao longo do século XX.

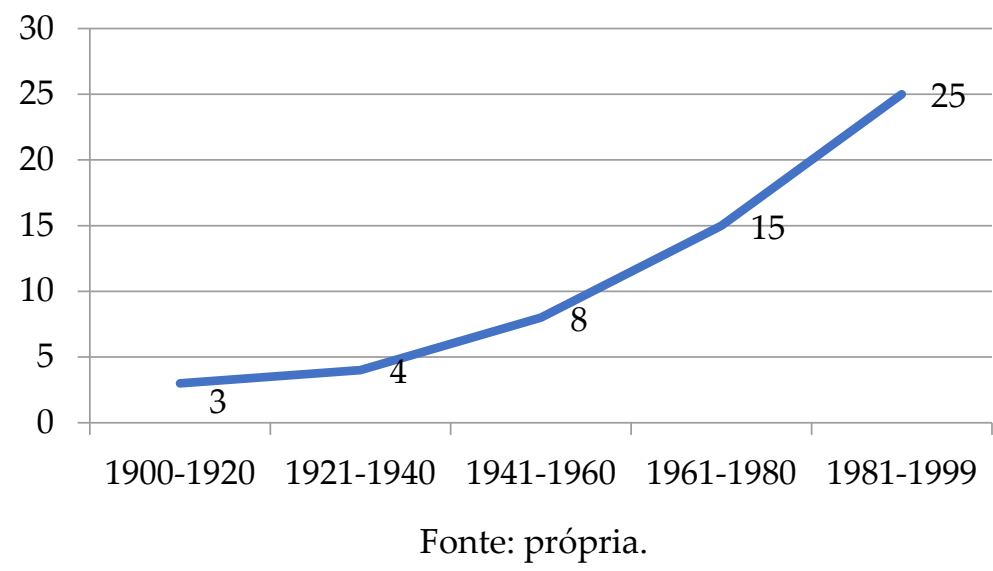

Ainda assim, é importante ter a consciência de que a escassa quantidade de exemplares mais antigos pode ter sido resultado do método adotado na presente pesquisa, em que a identificação dos manuais foi feita, majoritariamente, através de motores de busca on-line e pelo acesso a apenas bibliotecas físicas nacionais, as quais por serem localizadas em um país de fala não hispânica, possivelmente não possuem um acervo em língua espanhola tão antigo quanto os que poderiam ser encontrados em países hispânicos.

\subsection{Autoria}

Também consideramos as informações referentes ao número de autores envolvidos na produção das gramáticas e, com base nesse dado, foi possível verificar os casos de reincidência de autores, ou seja, de autores que produziram - ou ajudaram a produzir - mais de uma obra. Das 108 gramáticas encontradas, 92 apresentam o nome de apenas um autor, enquanto o restante apresenta dois ou mais autores.

Quanto à reincidência, verificamos que dos 114 autores presentes, somente 11 têm seu nome em mais de uma gramática, sendo que a Real Academia Española (RAE) apresenta o maior número de reincidências: cinco obras. $\mathrm{O}$ restante dos autores reincidentes apresenta apenas duas ocorrências cada. 
A Real Academia Española foi a única autoria institucional encontrada no corpus compilado. Tal resultado demonstra a forte presença da RAE como entidade conhecida por nortear o "bem falar" na língua espanhola. As cinco obras encontradas que são de sua autoria apresentam dispersão significativa na linha do tempo, tendo obras pertencentes a ela desde o século XVIII - desde sua fundação (1714) - até o presente século, como mostra o Quadro 1.

Quadro 1 - Das gramáticas da RAE.

\begin{tabular}{|c|c|}
\hline Publicação & Gramática \\
\hline $\mathbf{1 7 7 1}$ & Gramática de la lengua castellana. \\
\hline $\mathbf{1 8 5 7}$ & Compendio de la gramática de lengua castellana. \\
\hline $\mathbf{1 9 7 3}$ & $\begin{array}{c}\text { Esbozo de una nueva gramática de la lengua } \\
\text { española. }\end{array}$ \\
\hline $\mathbf{2 0 0 9}$ & Nueva gramática de la lengua española. \\
\hline 2010 & Manual de la Nueva Gramática de la Lengua \\
& Española. \\
\hline
\end{tabular}

Fonte: própria.

A recorrente autoria de gramáticas atribuídas à RAE põe mais uma vez em evidência o lugar de destaque da Espanha e, mais especificamente, de Madri - cidade que sedia a instituição - no processo de normatização do castelhano. Como já apontamos, os dados deste estudo mostraram a maior recorrência geral de elaboração de gramáticas nessas localidades.

\subsection{Finalidade}

$\mathrm{Na}$ última etapa de análise do corpus, restringimo-nos às gramáticas que conseguimos obter algum acesso a seu conteúdo, seja ele total ou parcial. Ao todo, foram analisadas 52 gramáticas, sendo 44 com possibilidade total de acesso e 8 com possibilidade apenas parcial.

A existência desse crivo foi de extrema necessidade, posto que aqui analisamos qual o objetivo dos manuais, ou seja, qual o seu direcionamento teórico e qual a 
finalidade proposta pelos autores ao produzi-los. É válido ressaltar que as informações encontradas e discutidas nesse segmento nos permitem visualizar, pela disposição do conteúdo apresentado, como o autor e como o público de sua época provavelmente entendiam a produção de gramáticas em língua espanhola.

Para compreender e categorizar essas gramáticas considerando o propósito, foram analisados, em cada uma, os seguintes elementos: título, índice e prólogo/introdução. Verificamos também, nessa análise, além de informações sobre o direcionamento teórico da obra, se havia alguma parte dedicada ao conceito de norma, seja mais explícito - um tópico ou capítulo dedicados a esse tema - ou mais implícito - aproximando-se a essa ideia sem utilizar os termos técnicos.

Ao final, as 52 gramáticas analisadas foram separadas em oito categorias: descritiva, didática, histórica, normativa, resumo e teórica. Essas categorias foram criadas baseadas nas descrições encontradas nas gramáticas e dizem respeito ao principal objetivo da obra analisada.

Foram classificadas como descritivas aquelas gramáticas que se propuseram a descrever o funcionamento da língua espanhola e que deram algum destaque à modalidade falada. Foram consideradas didáticas, por sua vez, aquelas que apresentaram objetivo de explicar o conteúdo gramatical com fim escolar. As classificadas como históricas foram as que se atentaram ao registro das mudanças sofridas pela língua espanhola ao longo de sua existência. Foram consideradas normativas as gramáticas que se propuseram a explanar e a apresentar as regras presentes na língua, de modo a orientar o leitor a seguir o que o autor entendeu por correto. Classificamos como resumo as obras que apresentaram explicação para tópicos específicos da gramática em língua espanhola ou que a explicaram de maneira sucinta. Por fim, as gramáticas classificadas como teóricas foram as que se identificaram nominalmente com alguma corrente linguística ou filosófica específica 
(Funcionalismo, Gerativismo etc.). A incidência de cada tema pode ser observada no Gráfico 4:

Gráfico 4 - Da incidência das categorias de finalidade.

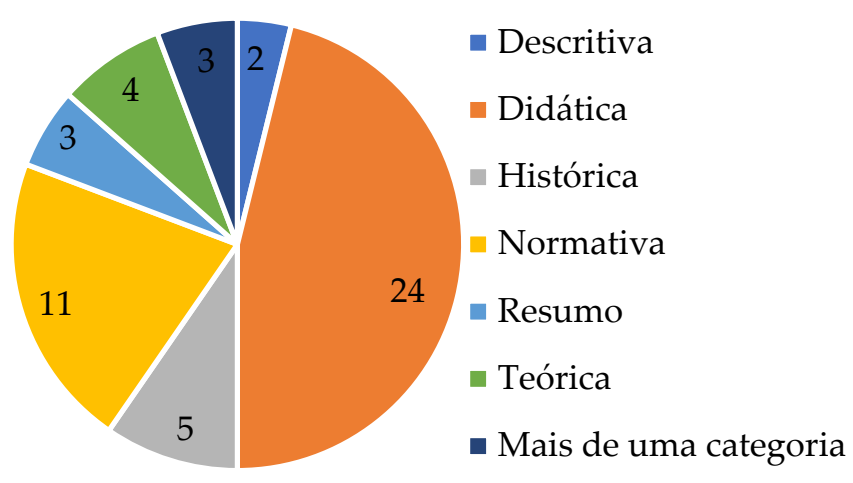

Fonte: própria.

Como observado no gráfico, o maior número de gramáticas está na categoria didática (24 gramáticas), referente a quase metade das obras analisadas. A segunda categoria que se destaca é a de gramáticas normativas, que somam 11 de 52 . Ainda de acordo com o gráfico, é possível perceber que três dessas gramáticas foram classificadas como pertencentes a mais de uma categoria. Delas, duas apresentam classificação normativa e uma apresenta a didática, o que reforça a grande incidência dessas duas categorias.

Quanto à localização de cada tema na linha do tempo, verificamos que os dois mais incidentes - didático e normativo - não registram ocorrência em apenas um século, mas estão presentes em todos os séculos em que foram publicadas as gramáticas que encontramos. No entanto, há uma diferença; enquanto as gramáticas normativas apresentam expressão maior nos séculos iniciais, as gramáticas didáticas apresentam maior frequência do século XIX em diante. Evidentemente, o crescimento na produção de gramáticas didáticas demonstram a crescente preocupação com o ensino do idioma, tanto como língua materna, como língua estrangeira. 
As gramáticas aqui classificadas como históricas, por outro lado, aparecem a partir do século XX. As descritivas, no final do século XX e as teóricas, a partir da década de 1970. É nessa década, também, que temos as três ocorrências de gramáticas classificadas como resumo. Assim, foi possível inferir que os dois séculos mais recentes apresentam maior variedade de abordagens na produção de gramáticas.

Vale comentar que foi visto o adjetivo "filosófico" sendo utilizado para caracterizar o viés adotado pelos autores em muitas gramáticas produzidas no século XIX. Também encontramos, nesse mesmo recorte temporal, alguns autores comentando a necessidade de elaborar gramáticas que se baseassem no comportamento linguístico escrito dos autores espanhóis de maior prestígio, ao invés de regras muitas vezes criadas fundamentadas no referencial da língua latina. Esse movimento se justifica pela forte influência francesa na produção do conhecimento europeu nessa época, principalmente de gramáticas.

Segundo Calero Vaquera (2016), a influência predominantemente política foi fator importante para que diversas obras de pensadores e de gramáticos franceses passassem a ser importadas e traduzidas para o espanhol, apesar das restrições religiosas estabelecidas pelo governo. Assim, muitas gramáticas de língua espanhola que foram produzidas nesse período têm referências diretas ao modelo cunhado pelos franceses ou mesmo enxergaram, nesse movimento, um sinal de que se deveria criar um modelo também específico de gramática para a língua espanhola.

Esse é o caso da Análisis lógica y gramatical de la lengua española, de Juan Calderón, publicada em 1843. Esse manual foi criado com o propósito de realizar uma nova análise da estrutura da língua espanhola. Seu autor diz, nas considerações iniciais, que esse objetivo nasce de uma necessidade maior, que seria a de registrar e de disponibilizar a língua de maneira mais esquematizada, como já faziam os franceses.

Considerando a menção feita ao conceito de norma linguística, dividimos as gramáticas em três categorias: as que mencionam explicitamente o termo norma e o 
discutem; as que não o mencionam, mas apresentam comentário que pode ser compreendido como a visão do autor sobre norma linguística e, por último, aquelas que não apresentam qualquer tipo de referência ao conceito de norma. Nessa categorização, observamos que mais da metade das gramáticas analisadas - 33 enquadram-se na última categoria citada. 14 gramáticas não mencionam explicitamente e as outras 5 o fazem.

Dentre as cinco gramáticas que discutem explicitamente o conceito de norma, merece destaque a obra de Francisco A. Marcos Marín, intitulada: "Aproximación a la gramática española", publicada em 1983. Trata-se de uma gramática produzida com finalidade predominantemente teórica, como pontua o autor, na introdução da obra. Produzida no final do século XX, já apresenta terminologia própria da Linguística atual em seu prefácio, inclusive comentando a existência de diferentes concepções de gramática.

Por sua vez, as gramáticas que não citam exatamente o conceito de norma, mas que discutem ideias próximas foram produzidas a partir do século XVIII. De 14 gramáticas presentes nessa categoria, 10 foram publicadas no século XX. Temos aqui, portanto, mais uma evidência da necessidade de discutir o que seria considerado ideal nos manuais produzidos, tendo em vista o crescente desejo de reformulação das gramáticas em língua espanhola, influenciado pelo movimento que ocorria simultaneamente na França. Por fim, as gramáticas que não discutem o conceito de norma também foram publicadas em diversas datas, não somente a partir de um período.

\section{Considerações finais}

O desenvolvimento do presente estudo permitiu o contato e a análise de algumas gramáticas de língua espanhola, desde a primeira proposta conduzida por Antonio de Nebrija, no século XV, até os manuais mais contemporâneos. Através da 
análise de dados de cada manual, foi possível extrair informações importantes a respeito do uso e da produção de gramáticas do castelhano ao longo do tempo.

Ao estudar os fatores extratextuais presentes na produção das 108 gramáticas, mostramos aspectos relevantes sobre a gramaticografia espanhola. As informações sobre o local de publicação das obras revelaram que está localizado na Espanha o maior mercado editorial e, por conseguinte, onde se publicam mais gramáticas de língua espanhola, sendo a RAE a autora mais reincidente. As informações sobre a origem geográfica dos autores dos manuais encontrados possibilitaram enxergar quais os principais países e/ou regiões envolvidos na produção das gramáticas: Espanha e Argentina. Havendo ainda participações menos expressivas, porém significativas, de países não hispanófonos, como os Estados Unidos e o Brasil.

Os dados referentes ao ano de publicação, por sua vez, revelaram a distribuição dos manuais ao longo do tempo, mostrando que no século XX foi publicada a maioria das gramáticas aqui analisadas (59). Nossos dados ainda revelaram que o processo de crescimento na produção de gramáticas iniciou-se no século XIX e manteve uma tendência sempre ascendente ao longo das décadas do século XX até os dias atuais. Sobre o fator "finalidade", vimos que o maior número de gramáticas assumiu um viés didático, seguido pelo viés normativo.

Tais informações configuram grande importância para pensar a norma linguística, posto que ajudam a esclarecer qual a visão dos autores e da sociedade, como um todo, em cada país e em cada recorte temporal. Com esses dados, é possível traçar uma linha do tempo e compreender como se deram as mudanças de visão sobre a língua espanhola e sobre a pertinência da produção de manuais dessa língua, seja como língua materna ou como língua estrangeira.

Com estudos futuros mais aprofundados - seja das obras presentes neste corpus ou de outras que venham a incorporá-lo -, será possível encontrar maior quantidade 
de dados que possam contribuir para a construção da história das gramáticas de língua espanhola.

\section{Referências}

ALÉONG, S. Normas linguísticas, normas sociais: uma perspectiva antropológica. In: BAGNO, M. (org.). Norma linguística. 2 ed. Tradução de Marcos Bagno. São Paulo: Loyola, 2011. p. 141-170.

BAGNO, M. Nada na língua é por acaso: por uma pedagogia da variação linguística. 2 ed. São Paulo: Parábola, 2007.

CALERO VAQUERA, M. L. Inicios y desarrollo de la gramática escolar en la tradición hispánica (siglo XIX). Revista Philologica romanica. v. 15-16, 2016. Disponível em: http://www.romaniaminor.org/ianua/Ianua15-16/05.pdf. Acesso em: 8 nov. 2018.

COSERIU, E. Sistema, norma y habla. In: COSERIU, E. Teoría del lenguaje y lingüística general. 3 ed. Madrid: Gredos, 1962.

MÚGICA, N. Acerca de la tensión norma - variación lingüística: Sintaxis, morfología, léxico. Revista virtual de estudos da linguagem, v. 5, n. 9, 2007. Disponível em: www.revel.inf.br/downloadFile.php?local=artigos\&id=101\&lang=pt. Acesso em: 5 mai. 2019.

PIETROFORTE, A. V. A língua como objeto da linguística. In: FIORIN, J. L. (org.). Introdução à linguística: objetos teóricos. São Paulo: Contexto, 2002. p. 75-94. 